\title{
Comparative analysis of JavaScript package managers - yarn and NPM
}

\section{Analiza porównawcza menadżerów pakietów JavaScript - yarn oraz NPM}

\author{
Michał Chodorowski* \\ Department of Computer Science, Lublin University of Technology, Nadbystrzycka 36B, 20-618 Lublin, Poland
}

\begin{abstract}
In this article, two leading solutions for managing packages in projects which are using JavaScript technology (yarn and npm) were subjected to a comparative analysis. As part of the implementation, two configuration files were created, one of which represents an empty application created on the basis of an application template based on the Angular framework in version 8 . The second file reflects an extensive web application based on the same framework, but with the addiction of over 100 dependencies. The research was focused on the time efficiency of both solutions.
\end{abstract}

Keywords: NPM; yarn; package manager; performance testing

\section{Streszczenie}

W niniejszym artykule analizie porównawczej poddano dwa wiodące rozwiązania służące do zarządzania pakietami w projektach wykorzystujących technologię JavaScript (yarn oraz npm). W ramach realizacji powstały dwa pliki konfiguracyjne, z których jeden reprezentuje pustą aplikację stworzoną na podstawie szablonu aplikacji opartej na szkielecie programistycznym Angular w wersji 8. Drugi plik odzwierciedla rozbudowaną aplikację internetową opartą o ten sam szkielet programistyczny, lecz z dodatkiem ponad 100 zależności. Badania ukierunkowane zostały na wydajność czasową obu rozwiązań.

Slowa kluczowe: NPM; yarn; menadżer pakietów; testy wydajnościowe

${ }^{*}$ Corresponding author

Email address: mic.chodowrowski@gmail.com (M. Chodorowski)

C) Published under Creative Common License (CC BY-SA v4.0)

\section{Wstęp}

Wraz z postępującym coraz szybciej zjawiskiem cyfryzacji, w naturalny sposób rośnie zapotrzebowanie na tworzenie szeroko rozumianego oprogramowania. To z kolei powoduje szybszy rozwój języków programowania, szkieletów, architektury oraz narzędzi do wytwarzania oprogramowania. Obecnie na rynku istnieje dostęp do bardzo wielu narzędzi, które mają za zadanie ułatwiać pracę programistom, często przez oszczędność czasu, który jest największym kosztem w całym procesie wytwarzania oprogramowania. Z tego powodu, przed przystąpieniem do pisania kodu, zespoły projektowe zastanawiają się nad doborem technologii oraz narzędzi, przy pomocy których będą tworzyć projekt. Jednym z fundamentalnych i niezbędnych narzędzi, bez których żadna współczesna aplikacja internetowa nie może się obyć, to menadżer pakietów. Wydawać by się mogło, że to mało istotna kwestia, ponieważ zarówno wybrany do analizy yarn oraz NPM, są rozwiązaniami używanymi przez miliony programistów na całym świecie. Jednak, przyglądając się bliżej tworzeniu oprogramowania można zaoszczędzić nawet kilka sekund na często wykonywanej operacji, to na przestrzeni dłuższego okresu czasu, oraz biorąc pod uwagę fakt, że nad daną aplikacją nie pracuje nigdy tylko jeden programista, zyskać można wiele godzin, które można by przeznaczyć na programowanie zamiast na czekanie. Wyniki analizy porównawczej zawarte w tym artykule mogą pomóc i oszczędzić wiele godzin koniecznych do wykonania analiz NPM i yarn.

\section{Cel badań i hipoteza}

Do badań wykorzystano dwa testowe pliki konfiguracyjne oparte o ten sam szkielet programistyczny, lecz z różną liczbą zależności, które zostały dobrane tak aby pierwszy plik konfiguracyjny odwzorowywal pustą aplikację zawierającą tylko niezbędne zależności, a drugi odwzorowywał rozbudowaną aplikację. Celem badań było przeanalizowanie wydajności czasowej tych dwóch rozwiązań.

Za hipotezę badawczą przyjęto:

Pomimo faktu, iz npm jest narzędziem chętniej wybieranym przez programistów, to yarn jest lepszym wyborem pod względem wydajności czasowej $w$ aplikacjach zawierających duża ilość pakietów.

\section{Systemy zarządzania pakietami JavaScript}

\subsection{NPM}

NPM (ang. „Node Package Menager”) jest domyślnym menadżerem pakietów dla środowiska uruchomieniowego Node.js dla języka JavaScript [1]. NPM dzieli się na dwie główne części [2]:

- CLI (ang. Command-Line Interface) -interfejs wiersza poleceń - narzędzie do pobierania oraz do udostępniania pakietów;

- internetowe repozytorium - zawiera pakiety JavaScript [3], które zostały stworzone i opublikowane przez społeczność programistów, którzy udostępnili swoje rozwiązania dla szerszego grona odbiorców. 


\section{Instalacja}

Instalacja NPM sprowadza się do zainstalowania Node js, korzystając $\mathrm{z}$ oficjalnej strony producenta. NPM zostaje automatycznie zainstalowany wraz z Node js.

\section{Skrypty NPM}

Plik konfiguracyjny (szerszy opis znajduje się w rozdziale 3.3), wspiera własność scripts (Listing 1), która może być zdefiniowana w celu uruchomienia CLI, w celu zainstalowania pakietów, wykonania konkretnej operacji, lub zestawu operacji. Często programiści definiują takie skrypty, aby nie trzeba było za każdym razem wykonywać długich sekwencji wywołań poszczególnych komend przez CLI, usprawnić sobie prace i zaoszczędzić czas poprzez wywołanie jednego skryptu, który zadziała automatycznie wraz z wywołaniem np. komendy npm install.

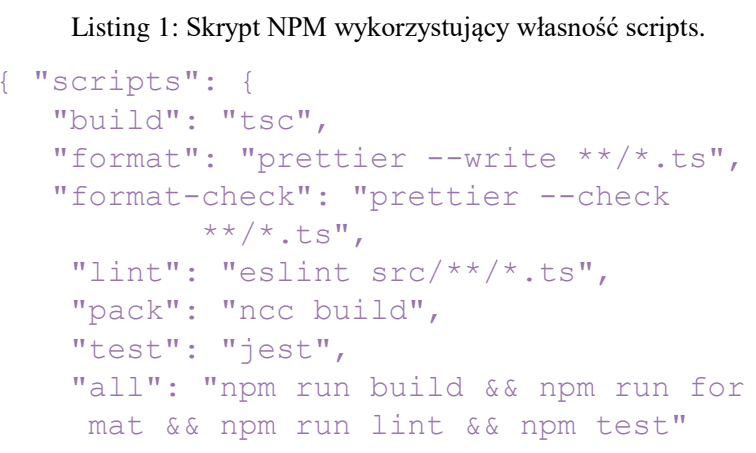

\section{Semantyka wersjonowania}

W celu zapewnienia niezawodności, funkcjonowania oraz bezpieczeństwa projektu JavaScript, za każdym razem, gdy dokonywane są znaczące zmiany w jakimś pakiecie, zalecane jest publikowanie nowej wersji pakietu ze zmienionym numerem wersji w pliku konfiguracyjnym pozostającym $\mathrm{w}$ zgodności $\mathrm{z}$ dyrektywami semantyk NPM. Dokładne przestrzeganie semantyki wersjonowania pomaga innym programistom, którzy polegają na danym pakiecie, zrozumieć jakie zmiany zostały dokonane, i czy wskutek tych zmian Ci programiści muszą dostosowywać swoją aplikację tak aby nadal działała prawidłowo, $\mathrm{z}$ nową wersją pakietu. Zwiększenie numeru wersji jest zalecane, zwłaszcza jeżeli zmiany zrywają jakąkolwiek zależność lub zmieniają układ zależności. Zmiany tego typu są w stanie uszkodzić cały projekt.

\section{Plik blokady}

Plik blokady [5] używany jest w celu wyznaczenia dokładnej wersji zależności, która musi zostać użyta w danym projekcie, aby zapewnić jego poprawne działanie. Jeżeli w pliku blokady (package-lock.json) nie została zdefiniowana dokładna wersja, którejkolwiek z zależności - w takiej sytuacji zostanie pobrana naj- nowsza stabilna wersja danej zależności. Posiadanie pliku blokady jest szczególnie ważne na serwerach CI (ang. „Continous Integration”), gdzie spoczywają produkcyjne wersje aplikacji. Najważniejsze komendy NPM przedstawia Tabela 1.

Tabela 1: Najczęściej używane komendy w NPM CLI

\begin{tabular}{|l|l|}
\hline \multicolumn{1}{|c|}{ Komenda } & \multicolumn{1}{c|}{ Opis dzialania } \\
\hline npm install & Instaluje zależności \\
\hline npm ci & Generuje produkcyjną wersje projektu \\
\hline npm audit & Skanuje projekt w poszukiwaniu zależności \\
\hline $\begin{array}{l}\text { npm audit } \\
\text { fix }\end{array}$ & Automatyczna naprawa podatności \\
\hline
\end{tabular}

\subsection{Yarn}

Yarn jest menadżerem pakietów JavaScript, który został wprowadzony przez Facebooka w 2017 roku. Obecnie wspiera go również Google. Yarn stał się głównym substytutem dla istniejącego już na rynku konkurencyjnego rozwiązania NPM. Yarn jest w pełni kompatybilny wstecz ze strukturą NPM [4].

Powody, dla których zespół Facebook’a zdecydował się na stworzenie własnego menadżera pakietów Yarn:

- możliwość działania $\mathrm{w}$ trybie bez dostępu do internetu, ponieważ Yarn posiada mechanizm zapamiętywania pakietów w pamięci podręcznej, dzięki czemu raz załadowane pakiety, zostają w tzw. cache, zamiast być pobierane ponownie, co przekłada się bezpośrednio na wydajność czasową,

- uruchamianie instalacji domyślnie w trybie deterministycznym, dzięki czemu struktura folderu zależności na każdej maszynie pozostaje identyczna. Zabieg ten zapobiega powstawaniu tzw. ,piekła zależności”, zwłaszcza gdy nad projektem pracuje w danym momencie wielu programistów jednocześnie, na różnych maszynach. Piekło zależności (ang. dependency hell) - potoczny termin używany przez programistów, który określa błędnie zdefiniowane lub trudne do spełnienia zależności, uniemożliwiające lub utrudniające poprawną instalacje lub działanie aplikacji.

\section{Instalacja}

W celu zainstalowania Yarn wystarczy posiadać Node.js na maszynie, na której odbywać się będzie instalacja. Yarn jest pakietem dostępnym w repozytorium pakietów NPM. Aby zainstalować go globalnie (posiadając Node.js) wystarczy wykonać komendę:

npm install -g yarn

\section{Skrypty yarn}

Yarn podobnie do NPM ma możliwość uruchamiania zdefiniowanych skryptów w pliku konfiguracyjnym, jednak yarn umożliwia programiście przekazanie jako wartość cały plik JavaScript zawierający skrypt, który ma się uruchomić po podaniu klucza, pod którym zapi- 
sany został w pliku konfiguracyjnym. Służy do tego komenda yarn run <nazwa_skryptu>.

Listing 2: Przypisanie skryptu do pliku konfiguracyjnego.

"scripts" :

"build-project": "node build-project.js"

W przypadku wywołania komendy yarn run build-project

zostanie uruchomiona komenda wywołująca instrukcję znajdujące się w pliku o tej samej nazwie, z rozszerzeniem js. Nazewnictwo skryptów yarn przekładać się może na moment ich wywołania. Przykładowo nazwa skryptu zawierająca frazę preinstall spowoduje, że skrypt zostanie wywołany przed zainstalowaniem pakietu, natomiast w przypadku fraz postinstall, install, postinstall, prepublish, prepare skrypt zostanie wywołany po zakończeniu instalacji pakietu.

\section{Plik blokady}

W momencie, w którym do zarządzania pakietami używany jest yarn, plik blokady zostaje wygenerowany automatycznie, co jest olbrzymią zaletą tego rozwiązania. Plik blokady tworzony przez yarn nosi nazwę yarn.lock. Kolejną zaletą jest fakt, iż za każdym razem, gdy uruchamiana jest komenda yarn install, plik blokady jest aktualizowany w sposób automatyczny. Plik blokady w yarn, podobnie jak w przypadku NPM, pozwala programistom uniknąć zjawiska zwanego piekłem zależności. Warto zwrócić uwagę na złożoność oraz mnogość informacji, które dostarcza programistom plik blokady yarn. Plik ten zawiera nazwę pakietu, wersję, link do rejestru repozytoriów, hash integralności oraz zależności, które bazują na tym pakiecie.

\section{Semantyka wersjonowania}

Yarn respektuje identyczną politykę wersjonowania co NPM. Dokładniejszy opis tej semantyki podano w rozdziale 3.1.

\subsection{Plik konfiguracyjny}

Plik konfiguracyjny (package.json) - każdy projekt napisany w JavaScript, niezależnie od tego czy jest to pełnoprawna aplikacja serwerowa napisana z Node.js, czy jest to zwykła aplikacja internetowa, może zostać skondensowana do pakietu NPM, zawierającego swoje własne informacje o tym pakiecie oraz swój własny plik konfiguracyjny, który opisuje ten projekt. Plik konfiguracyjny zostaje wygenerowany $\mathrm{w}$ momencie wywołania komendy npm init, inicjalizującej projekt JavaScript $\mathrm{z}$ domyślnymi metadanymi projektowymi:

- name: nazwa projektu lub biblioteki,

- version: wersja projektu, która zazwyczaj jest pomijana, ponieważ w większości przypadków nie ma konieczności jej ustawiania na tym etapie, lub usta- wiana jest później bazując np. na dokumentacji projektowej,

- description: opis projektu,

- licenses: licencja jaką objęty jest tworzony projekt.

\section{Analiza porównawcza}

Kryteria, które uwzględniono w prowadzonej analizie porównawczej to [7]:

- instalacja,

- wydajność,

- prędkość,

- niezawodność,

- komendy CLI,

- ilość logów,

- ilość zajmowanego miejsca na dysku przez folder zależności,

- popularność,

- bezpieczeństwo.

Instalacja NPM oraz instalacja yarn została przedstawiona odpowiednio $\mathrm{w}$ rozdziałach 3.1. oraz 3.2. Porównując oba te procesy stwierdzono, że NPM jest prostszy $\mathrm{w}$ instalacji. Porównania wydajności znajduje się w rozdziale 5, a wyniki przedstawiono w rozdziale 6 .

Obydwa rozwiązania pobierają pakiety z tego samego repozytorium, używając $\mathrm{w}$ przypadku yarn komendy yarn add a w przypadku NPM jest to npm install. Jednakże yarn jest o wiele szybszy niż NPM, co przedstawione zostało na Rysunku 2, ponieważ yarn instaluje wszystkie pakiety jednocześnie, ponadto yarn zapisuje pobrane pakiety w pamięci podręcznej, co zapobiega pobieraniu tego samego pakietu po raz drugi.

Menadżer pakietów, który stworzyła olbrzymia firma z sektora wytwarzania oprogramowania, ma pewne zalety (yarn), rozwiązanie to jest niezawodne i stabilne, dużo bardziej od NPM, ponieważ yarn używa pliku blokady, oraz deterministycznego algorytmu podczas instalacji każdego z pakietów, yarn również gwarantuje, że jeżeli coś działa w jednym środowisku programistycznym to będzie działało również na każdym innym. Jeżeli w yarn pojawia się jakiś błąd jest bardzo szybko naprawiany przez zespół programistyczny Marka Zuckerberga, czego niestety nie można powiedzieć na temat NPM.

Programiści muszą spędzić wiele godzin studiując komendy wykorzystywane w CLI, każdego narzędzia, w aspekcie menadżerów pakietów nie jest inaczej. W tabeli 2 przedstawiono komendy CLI dla obu pakietów.

Porównanie liczby logów zostało wykonane na podstawie instalacji tego samego pakietu (lodash). Yarn wygenerował 13 linii logów, natomiast NPM około 40 linii. Yarn generuje skondensowane logi, przekazując programiście tylko najważniejsze informacje, więc w liczbie logów wygrywa yarn.

Porównanie ilości zajmowanej przestrzeni dyskowej sprawdzono po wykonaniu komendy instalacyjnej i sprawdzeniu ilość zajmowanej przestrzeni dyskowej. 
Dla yarn folder node_modules zajmował $307 \mathrm{MB}$, zaś NPM 317 MB.

Wybierając menadżer pakietów należy również zwrócić uwagę na popularność rozważanego rozwiązania. Jeżeli wybrana technologia jest bardziej popularna, wówczas można liczyć na szerokie spektrum pomocy od społeczności. Jednak nie warto skreślać nowych rozwiązań, bowiem wszystko co jest nowe i sygnowane przez giganta technologicznego (Facebook w przypadku yarn), będzie zyskiwać szybko na popularności. Rysunek 1 przedstawia wykres liczby pobrań obu rozwiązań na przestrzeni ostatnich pięciu lat. Obserwując ten wykres bez trudu można określić, które rozwiązanie było popularniejsze na przestrzeni tych lat, ale również można dostrzec, że w roku 2020 popularność yarn znacząco wzrosła.

Tabela 2: Komendy CLI różne w obu menadżerach

\begin{tabular}{|l|l|l|}
\hline \multicolumn{1}{|c|}{ Komenda } & \multicolumn{1}{c|}{ NPM } & \multicolumn{1}{c|}{ yarn } \\
\hline Inicjalizacja projektu & npm init & yarn init \\
\hline $\begin{array}{l}\text { Uruchomienie testów dla } \\
\text { konkretnego pakietu }\end{array}$ & npm test & yarn test \\
\hline $\begin{array}{l}\text { Sprawdzenie czy, który- } \\
\text { kolwiek pakiet uległ } \\
\text { przedawnieniu }\end{array}$ & npm outdated & $\begin{array}{l}\text { yarn } \\
\text { outdated }\end{array}$ \\
\hline $\begin{array}{l}\text { Publikacja pakietu do } \\
\text { repozytorium NPM }\end{array}$ & npm publish & $\begin{array}{l}\text { yarn } \\
\text { publish }\end{array}$ \\
\hline Uruchomienie skryptu & npm run & yarn run \\
\hline $\begin{array}{l}\text { Czyszczenie pamięci } \\
\text { podręcznej }\end{array}$ & $\begin{array}{l}\text { npm cache } \\
\text { clean }\end{array}$ & $\begin{array}{l}\text { yarn } \\
\text { cache } \\
\text { clean }\end{array}$ \\
\hline $\begin{array}{l}\text { Proces logowania i } \\
\text { wylogowania }\end{array}$ & $\begin{array}{l}\text { npm login / npm } \\
\text { logout }\end{array}$ & $\begin{array}{l}\text { yarn login } \\
\text { / yarn } \\
\text { logout }\end{array}$ \\
\hline
\end{tabular}

Tabela 3: Przedstawia komendy CLI identyczne w obu menadżerach.

\begin{tabular}{|l|l|l|}
\hline Komenda & NPM & yarn \\
\hline $\begin{array}{l}\text { Instalacja } \\
\text { zależności }\end{array}$ & npm install & yarn \\
\hline $\begin{array}{l}\text { Instalacja } \\
\text { pakietu }\end{array}$ & $\begin{array}{l}\text { npm install [na- } \\
\text { zwa_pakietu] }\end{array}$ & $\begin{array}{l}\text { yarn add } \\
\text { [nazwa_pakietu] }\end{array}$ \\
\hline $\begin{array}{l}\text { Odinstalowanie } \\
\text { pakietu }\end{array}$ & $\begin{array}{l}\text { npm uninstall } \\
\text { [nazwa_pakietu] }\end{array}$ & $\begin{array}{l}\text { yarn remove [na- } \\
\text { zwa_pakietu] }\end{array}$ \\
\hline $\begin{array}{l}\text { Aktualizacja } \\
\text { środowiska }\end{array}$ & npm update & yarn upgrade \\
\hline $\begin{array}{l}\text { Aktualizacja } \\
\text { pakietu }\end{array}$ & $\begin{array}{l}\text { npm update [na- } \\
\text { zwa_pakietu] }\end{array}$ & $\begin{array}{l}\text { yarn upgrade [na- } \\
\text { zwa_pakietu] }\end{array}$ \\
\hline $\begin{array}{l}\text { Instalacja pakie- } \\
\text { tu globalnie }\end{array}$ & $\begin{array}{l}\text { npm install -- } \\
\text { global [na- } \\
\text { zwa_pakietu] }\end{array}$ & $\begin{array}{l}\text { yarn global add } \\
\text { [nazwa_pakietu] }\end{array}$ \\
\hline $\begin{array}{l}\text { Odinstalowanie } \\
\text { pakietu global- } \\
\text { nie }\end{array}$ & $\begin{array}{l}\text { npm uninstall -- } \\
\text { global [na- } \\
\text { zwa_pakietu] }\end{array}$ & $\begin{array}{l}\text { yarn global remove } \\
\text { [nazwa_pakietu] }\end{array}$ \\
\hline $\begin{array}{l}\text { Interaktywna } \\
\text { aktualizacja }\end{array}$ & $\begin{array}{l}\text { npm run upgrade- } \\
\text { interactive }\end{array}$ & $\begin{array}{l}\text { yarn upgrade- } \\
\text { interactive }\end{array}$ \\
\hline
\end{tabular}




\subsection{Charakterystyka zbioru danych pierwotnych}

Dane podchodzą $\mathrm{z}$ testów wydajnościowych przeprowadzonych na dwóch plikach konfiguracyjnych za pomocą biblioteki gnomon oraz z wykorzystaniem terminala, dla obu menadżerów pakietów. Wyniki otrzymano z dokładnością do $1 \mathrm{~ms}$. Biblioteka gnomon została wykorzystana do pomiaru czasów wykonania poszczególnych komend, wywoływanych za pomocą terminala.

\subsection{Algorytmy służące do obliczania poszukiwa- nych wartości}

Do obliczania poszukiwanych wielkości użyto wzoru na średnią arytmetyczną. Uzyskane wyniki zostały zaokrąglone do dwóch miejsc po przecinku i są zestawione w rozdziale 6 .

\subsection{Przeprowadzenie badań}

Przed przystąpieniem do badania wydajności czasowej menadżerów pakietów, upewniono się, iż żaden zbędny proces, obciążający środowisko badawcze nie pozostał włączony, sprawdzono również obciążenie środowiska badawczego i upewniono się, że żadna usługa sieciowa nie działa w tle i nie pobiera zasobów. Badania były przeprowadzone dla następujących scenariuszy:

- $\quad$ S1 - plik konfiguracyjny zawiera podstawowe zależności dla projektu Angular.

- $\quad$ S2 - plik konfiguracyjny zawiera dodatkowe zależności dla projektu Angular.

\section{Scenariusz S1 dla podstawowego projektu Angular}

1. Stworzono pusty projekt poprzez użycie komendy npm init dla NPM oraz yarn init dla yarn.

2. Wykonano komendy yarn install | gnomon dla folderu, w którym znajduje się projekt stworzony za pomocą yarn i analogicznie npm install | gnomon dla projektu utworzonego przez NPM.

3. Wykonano komendy npm update | gnomon, oraz yarn upgrade | gnomon.

\section{Scenariusz S2 dla rozbudowanego projektu Angular}

Procedura testowa jest zbliżona do S1, z tym, że zanim przystąpiono do wykonania testów, dodane zostało ponad sto dodatkowych zależności, aby odzwierciedlić wykonanie każdej z komend na rozbudowanym projekcie.

\section{Wyniki badań}

W Tabeli 4 przedstawiono średnie czasy wykonania scenariuszy S1 i S2 dla yarn, natomiast w Tabeli 5 - dla NPM. Rysunki 2 i 3 obrazują rezultaty uzyskane dla obu pakietów.
Tabela 4: Wydajność czasowa yarn

\begin{tabular}{|c|c|c|}
\hline Komenda CLI & $\begin{array}{c}\text { Średni czas } \\
\text { wykonania ko- } \\
\text { mendy dla S1 }\end{array}$ & $\begin{array}{c}\text { Średni czas } \\
\text { wykonania ko- } \\
\text { mendy dla S2 }\end{array}$ \\
\hline yarn install & $45,89 \mathrm{~s}$ & $107,4 \mathrm{~s}$ \\
\hline yarn upgrade & $19,9 \mathrm{~s}$ & $49,09 \mathrm{~s}$ \\
\hline
\end{tabular}

Tabela 5: Wydajność czasowa NPM

\begin{tabular}{|c|c|c|}
\hline Komenda CLI & $\begin{array}{c}\text { Średni czas } \\
\text { wykonania ko- } \\
\text { mendy dla S1 }\end{array}$ & $\begin{array}{c}\text { Średni czas } \\
\text { wykonania ko- } \\
\text { mendy dla S2 }\end{array}$ \\
\hline npm install & $125,8 \mathrm{~s}$ & $258,43 \mathrm{~s}$ \\
\hline npm update & $6,08 \mathrm{~s}$ & $19,4 \mathrm{~s}$ \\
\hline
\end{tabular}

\section{Wnioski}

$\mathrm{Na}$ podstawie przeprowadzonych badań wyciągnięto następujące wnioski:

- Yarn jest wydajniejszy pod względem pobierania wszystkich zależności z użyciem komendy instalacyjnej od NPM, niemal trzykrotnie w przypadku małych aplikacji internetowych oraz nieco ponad dwa i pół razy wydajniejszy w przypadku rozbudowanych aplikacji internetowych.

- NPM jest wydajniejszy pod względem aktualizacji pakietów od yarn, w przypadku zarówno małych aplikacji internetowych, ponad trzykrotnie jak i w przypadku rozbudowanych aplikacji, w przypadku których NPM, jest wydajniejszy ponad dwukrotnie.

- Pomimo faktu, iż NPM jest narzędziem chętniej wybieranym przez programistów, to yarn jest lepszym wyborem pod względem wydajności czasowej w aplikacjach zawierających dużą ilość pakietów.

- Wyniki uzyskane w artykule autorstwa Jacobs Alexander z 2019 roku, które nie dały jednoznacznej odpowiedzi, które rozwiązanie autor poleca do użytku, najbliżej tego wyniku w porównaniu tego autora był NPM. Co tylko potwierdza ogólnie znaną tezę, że w świecie programowania technologie zmieniają się bardzo dynamicznie. Nie inaczej jest w przypadku JavaScript, w 2019 roku NPM wiódł prym, a w 2020 prym wiódł yarn.

- Hipoteza postawiona na początku artykułu została potwierdzona.

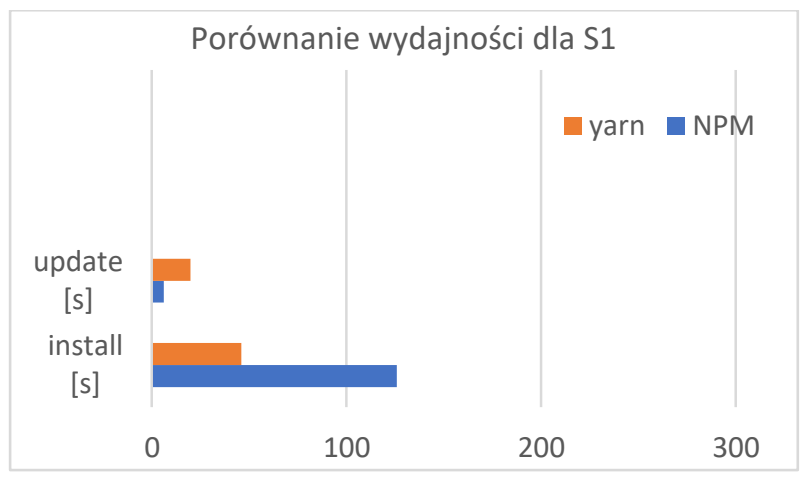

Rysunek 2: Porównanie wydajności dla aplikacji z podstawową liczbą zależności 


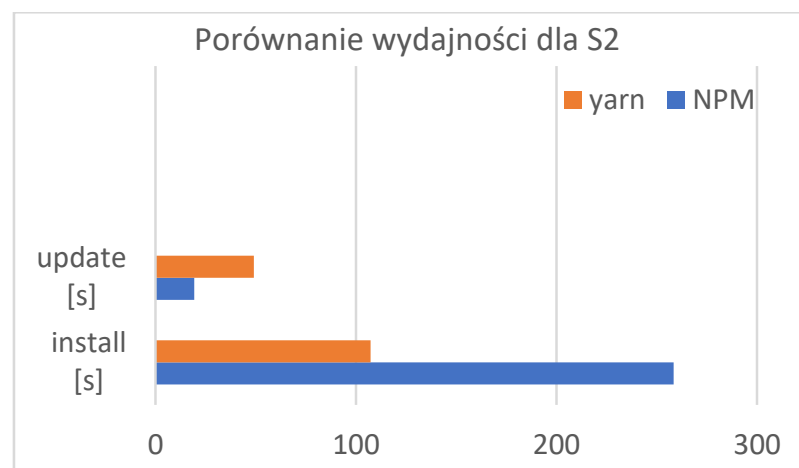

Rysunek 3: Porównanie wydajności aplikacji z rozbudowaną siatką zależności

Yarn osiągnął lepszy wynik od NPM w następujących kategoriach:

- bezpieczeństwo,

- ilość zajmowanej przestrzeni dyskowej,

- ilość produkowanych logów,

- niezawodność,

- prędkość,

- wydajność czasowa.

NPM okazał się lepszym rozwiązaniem pod kątem instalacji oraz popularności wśród społeczności programistów.

\section{Literatura}

[1] MSR '16: Proceedings of the 13th International Conference on Mining Software Repositories https://dl.acm.org/doi/ abs/10.1145/2901739.2901743, [24.01.2021].

[2] Charakterystyka NPM https://www.freecodecamp.org/ news/what-is-npm-a-node-package-manager-tutorial-forbeginners/, [03.01.2021].

[3] Działanie menadżerów pakietów JavaScript https://www.freecodecamp.org/news/javascript-packagemanagers-101-9afd926add0a/, [03.01.2021].

[4] Charakterystyka yarn https://engineering.fb.com/2016/10/ 11/web/yarn-a-new-package-manager-for-javascript/, [11.02.2021].

[5] E. Wittern, P. Suter, S, Rajagopalan, A look at the dynamics of the JavaScript package ecosystem, MSR'16: Proceedings of the 13 Conference of Mining Software Repositories, (2016) 351-361, https://dl.acm.org/ doi/10.1145/2901739.2901743.

[6] A. Jacobs, Comparsion of Javascript Package Managersm 2019, https://www.theseus.fi/handle/10024/227945, [24.01.2021].

[7] Wykres popularności obu rozwiązań https://www.npmtrends.com/npm-vs-yarn, [24.01.2021]. 